\title{
Causes of Students' Violence at AL-Hussein Bin Talal University
}

\author{
Theeb M. Alrawwad ${ }^{1} \&$ Atif Eid Alrfooh ${ }^{1}$ \\ ${ }^{1}$ Faculty of Educational Sciences, Al-Hussein Bin Talal University, Ma'an, Jordan \\ Correspondence: Atif Eid Alrfooh, Faculty of Educational Sciences, Al-Hussein Bin Talal University, P.O. Box \\ 20 Ma'an, Jordan. Tel: 962-3217-9000. E-mail: dr_atifr@yahoo.com
}

Received: December 12, 2013 Accepted: February 8, 2014 Online Published: February 20, 2014

doi:10.5539/ies.v7n3p30

URL: http://dx.doi.org/10.5539/ies.v7n3p30

\begin{abstract}
This study aimed at identifying the causes of students' violence from the student's point of view, and also aimed at investigating the proper solutions to reduce the spread of violence at AL- Hussein Bin Talal University. The study sample consisted of (906) male and female students from Al-Hussein Bin Talal University, who have enrolled the summer semester during the academic year (2011/2012). The sample was selected randomly from faculties of Arts, Science, Information Technology, Education, Engineering, Tourism Archaeology, Business Administration \& Economics and Faculty of Nursing. Respondents -both males and females- belong to different academic years: first, second, third and fourth year. In order to invistigate the most significant reasons of violence, information were gathered through a questionnaire of a five point scale for the measurement of the scale, and the results had showed that the major causes of violence as reported by the respondents were tribal fanaticism, nepotism, tribal effects on the society, not respecting students and improper treatment, psychological stress and disorders, weakness of the religious restrain and bad investment of free time.
\end{abstract}

Keywords: research, violence, university, educational process, social problems, fantasicm

\section{Introduction}

The phenomenon of violence requires attention, as it is spreading in developed and developing countries as the same, and it has its political, economic, social, cultural and psychological aspects, as defined by all human societies, and this rapid spread of this phenomenon had affected the political, social and economical environment, thus, many sociologists sees that reforming any society will be through the control of this phenomenon within the community.

In recent years, the world has witnessed a widespread of violence in all parts of the society in general, and at universities in particular, in addition to an increasing number of crimes, regardless of countries, areas or origins. On the other hand, violence Intensity and effect may differentiate according to the degree of awareness and culture, urbanization, as well as social classes and life style (Shwiehat \& Akroush, 2010).

Violence has become a serious problem affecting not only students, families, and educational construction, but also it affects the overall society.

It is doubtless that successful educational process, whether in schools or universities, requires a secure and safe environment, and to achieve this goal, all society members have to combine efforts and work together and cooperate in order to stop this threat and prevent its negative impact on the society (Wiley \& Sons, 2001).

Although violence is practiced everywhere and is not limited to a specific class or age, It is notable that violence spreads at universities more than other institutions. University community is distinguished from other communities, affects and is affected by other phenomenon, and what happens inside the campus is reflected outside.

\subsection{Definitions}

Student violence is an offensive and compelling form of behavior which includes physical or psychological harm, financial exploitation, damaging other's properties which are practiced by some students against colleagues or instructors. It also includes breaking university rules and damaging its properties (Hawamdeh, 2007).

\subsection{Causes of Violence}

It was not strange to hear, especially in the last decades, that a student hurts or shots one of his colleges or that 
the university administration seeks the public security help to stop a big fight or quarrel. Throughout university stages, student rarely would not see or participate in any dispute or quarrel. In most cases, tribal fanaticism is the most significant cause to encourage violence, in addition to that, the spread of masculinity in the Arab world in general, and in the Jordanian community specifically. Sometimes, long hours of free time may also lead to the behavior of violence (Kim, 2005).

Reasons also could be attributed to domestic violence and family dysfunction as significant factors leading to occurrence of violence among university students (Okour \& Hijazi, 2009).

Generally, violence as a social behavioral problem can be considered a result of several reasons such as social, psychological, environmental or a combination of all these factors.

It is notable that Social problems, poverty, unemployment, economic, political problems in addition to spread of drugs and alcohol are some of the most prominent elements that lead to violence, as well as other social problems (Hawamdeh, 2007).

Violence may also be the result of internal factors related to the university system, such as educational and administration policy, including bias, unfair dealing with students, punishment regulation.

The interaction between institutors and students also plays an important role in the occurrence of violence like: unfair marks giving, discrimination and preference of certain students (Hawamdeh, 2007).

\section{Study Hypothesis}

H1: There is a statistically significant effect between student's violence and university policies and management

$\mathrm{H} 2$ : There is a statistically significant effect between student's violence and students themselves and psychological, economical and social factors

H3: There is a statistically significant effect between student's violence and the reasons related to teaching staff

\section{Purpose of the Study}

This study aimed at identifying the causes of students' violence at AL-Hussein Bin Talal University from the student's point of view so as to accomplish these purposes:

- Identify the most significant reasons of violence according to the study results, and by the help of previous literature.

- Find out the proper solution to reduce the spread of violence at AL- Hussein Bin Talal University.

- Provide the responsible authorities at AL- Hussein Bin Talal University with some recommendations and helpful practices that could limitate the phenomenon of violence.

- Identify the relationship between students' violence and university policies, teaching staff and psychological, economical and social factors

\section{Importance of the Study}

This topic is very important, because violence is not limited to educational institutions, but it has also a disastrous influence on the social structure, so that it must be resisted.

As it is well known, the university is an integrated part of society, and youth is the most vital element. As violence is widely spread at universities, youth is the most affected party among other society components (Wiley \& Sons, 2001).

\section{Problem Statement}

In the educational processes and in studying the spread of violence, researchers had faced many difficulties and challenges in identifying the causes of violence and in finding out the suitable solutions, because this problem could not be attributed to one single reason and could not be understood from a cross-cultural perspective, rather it is complexity, sensitivity and it correlations with social and environmental aspects.

In addition, previous literature on the students' violence in universities arrived to various different causes, consequences, and recommendations. So this study concentrates on the most influential causes from the perspective of students, and tries to provide some recommended solutions related to violence.

Some of these difficulties occur because of the tribal constitution structure which marks the Jordanian society, in addition to the tribal fanaticism and different traditions, customs, , Social circumstances, and political regime which help in rooting fanaticism. Additionally, Lack of flexibility in the laws and strategies used universities; the nature of the university system as well as punishment system may also help to increase the phenomenon of 
violence.

\section{Literature Review}

Many studies were conducted on this field and discussed the impact of violence, and the following is a presentation of some of these studies:

Motoko (2001) study in the United States, entitled, "Violence in the middle school years in Japan and the United States: the impact of the academic competition on the students violent", where the researcher used three tools to get the data related to the data of the victims of the schools violence from (37) different nationalisms, as well as the survey data on (922) students, and the study results showed that violence prevails in 37 schools nationwide.

Aarot (2009) studyentitled "Schools discipline and its relationship with the violence phenomenon in the official Jordanian universities from the perspective of the students themselves", the study aimed at examining the relationship of the methods of the schools discipline with violence in the official Jordanian universities from the perspective of the students themselves, finding differences in the degree of violence among students who have been tuning with the violent methods that and others who have not been exposed to it.

The aim of a study conducted by (Okour \& Hijazi, 2009) was to investigate the relationship between domestic violence and violent behavior of university students in North Jordan. The study was applied in three universities using a sample of 1560 undergraduate students. The results showed that domestic violence and family dysfunction are some of the most significant factors leading to violence according to students who has participated in the study. It was also shown that participation in quarrels rates at the three universities during the last 3 years were high and has increased. According to student's opinions, The most common causes of students' violence were domestic violence in the first rank, then surrounding community, media and communication means, school, and finally university.

The aim of (Al-Louzi \& Farhan, 2009) study was to investigate the causes and consequences of violence according to students points of view and to find out the suitable solutions. The results revealed that tribal fanaticism and masculinity are the most significant causes of violence among students. In addition, it was found that students do not fear punishment rules applied by the university. Moreover, it was found that wasting free time and bad social circumstances also contribute in acquiring violent behavior. The study indicated that the most negative impacts of student's violence are damaging university properties and the spread of insecurity, as well as reflecting a negative image about the university. The study has also focused on the need to spread awareness among students and encourage them to increase the interaction between students, administrators and teaching staff. Furthermore, the concept of national Unity and toleration must be enhanced and respected as clarified in the study recommendations.

Al-Atiat (2010) study revealed (50) manners to apply non-violence, some were concerning the administrative level such as facilitating transportation means, avoiding nepotism, and freedom of expression. In respect of academic level, the manners included student's freedom to choose the instructor of the subject, involvement of students in researches and activation of academic guidance, in addition to the activation of scientific clubs. With regard to the socio-economic level, it was found that rising awareness in the local society and avoiding tribal and regional intolerance, justice in applying laws as well as holding cultural and religious trips is key factors that can help in limitation of violence at universities.

Alhawamdeh (2007) conducted a study that disscussed violence in Jordanian public and private universities from students' point of view. The aim of the study was to find out the prevalence rate of violence spread in Jordanian public and private universities and to find out the types of violence committed by students, in addition to the most obvious social consequences of violence on both of the university and community. The study also indicated the cultural roots which promote violence and the motivations behind this phenomenon.

Information was gathered through a questionnaire and a sample consisted of students of six Jordanian public and private universities. Finally, the study presents methods and recommendations to reduce this phenomenon.

It is noted those previous studies:

(1) Agreed on the importance of studying the issue of violence, especially in the educational institutions.

(2) Most of these studies agreed on the importance of the reduction of the violence phenomenon.

(3) Most of the studies agreed that the phenomenon of violence is a dangerous phenomenon, may lead to dire consequences if they were neglected.

(4) This study differs from previous studies as it is dealing with the development of educational strategy to reduce violence through analysing the impact of the economical and social factors in the Jordanian society. 


\section{Methods and Procedures}

\subsection{The Study Population}

The study population consists of all students who have registered for the summer semester at AL-Hussein Bin Talal University. The total number of students was 6471 from the faculties of Arts, Science, Information Technology, Education, Engineering, Tourism and Archaeology, Business Administration \& Economics and Faculty of Nursing.

\subsection{The Study Sample}

The study sample consisted of (906) male and female students from AL-Hussein Bin Talal University who have registered for the summer semester of the academic year 2011-2012. The respondents were selected randomly from all Faculty members and both genders. Number of male respondents was 422 while female respondents were 484.

Table 1 . The distribution of the study sample according to gender and faculty

\begin{tabular}{cccc}
\hline Faculty & \multicolumn{2}{c}{ Gender } & Sum \\
\cline { 2 - 3 } & Male & Female \\
\hline AD & 144 & 120 & 264 \\
ART & 46 & 86 & 132 \\
EDU & 22 & 62 & 84 \\
ENG & 104 & 74 & 178 \\
IT & 36 & 30 & 66 \\
NUR & 4 & 42 & 46 \\
SC & 42 & 62 & 104 \\
TRS & 24 & 8 & 32 \\
\hline Total & 422 & 484 & 906 \\
\hline
\end{tabular}

\subsection{Sample Characteristics}

\subsubsection{Gender}

Table 2. Sample characteristics according to gender

\begin{tabular}{lllll}
\hline Sex & Frequency & Percentage & Valid Percentage & Cumulative Percentage \\
\hline Male & 422 & $46.6 \%$ & $46.6 \%$ & $100 \%$ \\
Female & 484 & $53.4 \%$ & $53.4 \%$ & $53.4 \%$ \\
\hline Total & 906 & $100 \%$ & $100 \%$ & \\
\hline
\end{tabular}


Table 2 shows that 53.4 percent were females and 46.6 percent were males, so most of the samples are females.

\subsubsection{Faculty}

Table 3. Sample characteristics according to college

\begin{tabular}{lllll}
\hline Faculty & Frequency & Percentage & Valid Percentage & Cumulative Percentage \\
\hline AD & 264 & $29.1 \%$ & $29.1 \%$ & $29.1 \%$ \\
ART & 132 & $14.6 \%$ & $14.6 \%$ & $43.7 \%$ \\
EDU & 84 & $9.3 \%$ & $9.3 \%$ & $53.0 \%$ \\
ENG & 178 & $19.6 \%$ & $19.6 \%$ & $72.0 \%$ \\
IT & 66 & $7.3 \%$ & $7.3 \%$ & $79.9 \%$ \\
NUR & 46 & $5.1 \%$ & $5.1 \%$ & $85.0 \%$ \\
SC & 104 & $11.5 \%$ & $11.5 \%$ & $96.5 \%$ \\
TRS & 32 & $3.5 \%$ & $3.5 \%$ & $100 \%$ \\
\hline Total & 906 & $100 \%$ & $100 \%$ & \\
\hline
\end{tabular}

Table 3 shows that the highest rank is for College of Business Administration \& Economics with (29.1\%), then respectively in descending order College of Engineering (19.6\%), College of Arts (14.2\%), College of Science $(11.5 \%)$, College of Education (9.3\%), College of Information Technology (7.3\%), Faculty of Nursing (5.1\%), and finally College of Tourism and Archaeology faculty (3.5\%).

\subsubsection{Academic Level}

Table 4. Sample characteristics according to academic level

\begin{tabular}{lllll}
\hline Academic level & Frequency & Percentage & Valid Percentage & Cumulative Percentage \\
\hline 1 & 328 & $36.2 \%$ & $36.2 \%$ & $36.2 \%$ \\
2 & 316 & $34.9 \%$ & $34.9 \%$ & $71.1 \%$ \\
3 & 143 & $15.8 \%$ & $15.8 \%$ & $86.9 \%$ \\
4 & 119 & $13.1 \%$ & $13.1 \%$ & $100 \%$ \\
\hline Total & 906 & $100 \%$ & $100 \%$ & \\
\hline
\end{tabular}

Table 4 shows that most of the respondents are from the first and second academic year as $36.2 \%$ and $34.9 \%$ which forms $71.1 \%$, and only $28.9 \%$ for the third and fourth academic year as $15.8 \%$ and $13.1 \%$ respectively.

\section{Study Instrument}

The instrument used in the current study is a questionnaire developed to explore reasons of violence according to student's point of view at AL-Hussein Bin Talal University.

The questionnaire consists of two parts, the first included personal information as follows: student's faculty, gender, major, average and academic level. The second part included (29) question items involving four domains. Questions were classified according five-graded scale, and the results were analyzed using the SPSS.

\section{Statistical Analysis}

The data was analyzed by using the SPSS software (Statistical Package for the Social Sciences). Two types of statistics were used; qualitative and quantitative. The qualitative statistics included means, frequencies, percentages, and standard deviations to characterize the sample. Similarly, the qualitative statistics included one way ANOVA to test statistical differences between the means of responses by the qualitative variables of the respondents; and Cornobach's Alpha to measure the internal consistency among different statements of the 
ordinal scale.

\subsection{First Domain (Reasons Related to University Policies and Management)}

Table 5. Arithmetic means and standard deviations of the first domain

\begin{tabular}{lll}
\hline First Domain & AM & SD \\
\hline Q2: Nepotism & 4.4570 & 1.0600 \\
Q1:Absence of dialogue with students & 3.9371 & 1.0339 \\
Q4:Not respecting students and improper treatment & 3.8631 & 1.1510 \\
Q6: Credit hours systems which leads long free time hours & 3.8102 & 1.2638 \\
Q5: Registration system at the university & 3.7925 & 1.1851 \\
Q3: Weakness of social and academic direction of students & 3.7163 & 1.0203 \\
Q8: Procedures used in solving quarrels between students & 3.7108 & 1.1903 \\
Q7:Loan system & 2.9128 & 1.2114 \\
\hline
\end{tabular}

Table 5 indicates that means of subjects' responses are ranging from (4.45 to 2.91) with standard deviations (1.26 to 1.02) respectively. The results indicate different degrees of sample's agreement from high to low level. Question number 2 (the effect of nepotism) has the highest rank while question number 7 has the lowest rank. 9.2 Second Domain (Reason Related to Students Themselves and Related to Psychological, Economical and Social Factors)

Table 6. Arithmetic aeans, and standard deviations of the second domain

\begin{tabular}{lll}
\hline Second Domain & AM & SD \\
\hline Q11: Tribal fanaticism between students & 4.6921 & 1.7454 \\
Q10: The weakness of the religious restrain & 4.2881 & 1.0469 \\
Q13: Psychological stress and disorders & 3.8664 & 0.9764 \\
Q14: Emotional stress and disorders & 3.7450 & 1.1544 \\
Q16 Disputes resulting from emotional relationships & 3.6987 & 1.3158 \\
Q15: Social class of student's family & 3.5011 & 1.1792 \\
Q9: Low income of student's family & 3.4260 & 1.9140 \\
Q12: Jealousy & 3.2539 & 1.2212 \\
\hline
\end{tabular}

Table 6 indicates that means of subjects' responses are ranging from (4.69 to 3.25) with standard deviations (1.91 to 0.98 ) respectively. The results indicate different degrees of sample's agreement from high to low level. Question number 11 has the highest rank while question number 12 has the lowest rank. 


\subsection{Third Domain (Reasons Related to Teaching Staff)}

Table 7. Arithmetic means and standard deviations of the third domain

\begin{tabular}{lll}
\hline Third Domain & AM & SD \\
\hline Q20: Lack of motivation and the element of suspense & 4.3091 & 3.9353 \\
Q18: Lack of objectivity in marks giving & 3.9382 & 1.1038 \\
Q19: Unjustified bias to some students pinions & 3.8874 & 2.3870 \\
Q21: Ignoring students' demands and opinions & 3.7781 & 1.1421 \\
Q17: Inferior looking for students & 3.7075 & 1.0499 \\
Q22: Lack of participation in the lecture & 2.8046 & 2.8808 \\
\hline
\end{tabular}

Table 7 indicates that means of subjects' responses are ranging from (4.31 to 2.80) with standard deviations (3.94 to 1.05) respectively. The results indicate different degrees of sample's agreement from high to low level. Question number 20 has the highest rank while question number 22 has the lowest rank.

9.4 Fourth Domain (Reasons Related to Other Factors)

Table 8. Arithmetic means and standard deviations of the fourth domain

\begin{tabular}{lll}
\hline Fourth Domain & AM & SD \\
\hline Q24: Tribal effects on the society & 4.4989 & 0.7525 \\
Q23: Poverty & 4.1468 & 0.8484 \\
Q29: Means of communication as mobiles and the internet & 4.1093 & 1.0073 \\
Q26: Incitement from outside the university & 3.7936 & 1.3675 \\
Q25: Different political attitudes from outside the university & 3.6932 & 0.9976 \\
Q27: The effect of local and political events & 3.5751 & 1.0582 \\
Q28: Local and international media & 3.3709 & 1.1992 \\
\hline
\end{tabular}

Valid N (list wise) for tables $(5,6,7$ and 8$)$ is (906).

The above table indicates that means of subjects' responses are ranging from (4.50 to 3.37) with standard deviations (1.37 to 0.75 ) respectively. The results indicate different degrees of sample's agreement from high to low level. Question number 24 has the highest rank while question number 28 has the lowest rank.

\section{Results and Discussion}

\subsection{First Hypothesis}

There is a statistically significant effect between student's violence and university policies and management.

Table 5 shows that mean for the fist domain (university policies and management) is high, so there is a statistically significant effect between student's violence and university policies and management. 
Table 9. Significance level of the first domain (ONE SAMPLE TEST)

\begin{tabular}{|c|c|c|c|c|c|c|}
\hline & \multicolumn{6}{|c|}{ Test Value $=3.8$} \\
\hline & \multirow{2}{*}{$\mathrm{T}$} & \multirow{2}{*}{ Df } & \multirow{2}{*}{$\begin{array}{l}\text { Sig. } \\
\text { (2- tailed) }\end{array}$} & \multirow{2}{*}{$\begin{array}{l}\text { Mean } \\
\text { Difference }\end{array}$} & \multicolumn{2}{|c|}{ 95\% Confidence Interval of the Difference } \\
\hline & & & & & Lower & Upper \\
\hline VAR1 & -1.380 & 905 & 0.168 & -2.503 E-02 & $-6.06 \mathrm{E}-02$ & $1.056 \mathrm{E}-02$ \\
\hline
\end{tabular}

The above table shows that $\mathrm{Sig}=0.168$ more than $5 \%$ which means that there is a statistically significant effect between students violence and university policies and management.

\subsection{Second Hypothesis}

There is a statistically significant effect between student's violence and students themselves and psychological, economical and social factors.

Table 6 shows that mean for the second domain (students themselves and psychological, economical and social factors) is high so there is a statistically significant effect between student's violence and psychological, economical and social factors.

Table 10. Significance level of the second domain (ONE SAMPLE TEST)

\begin{tabular}{|c|c|c|c|c|c|}
\hline & \multicolumn{5}{|c|}{ Test Value $=3.8$} \\
\hline & \multirow[t]{2}{*}{$\mathrm{T}$} & \multirow[t]{2}{*}{ Df } & \multirow{2}{*}{$\begin{array}{l}\text { Sig. } \\
\text { (2- tailed) }\end{array}$} & \multirow{2}{*}{$\begin{array}{l}\text { Mean } \\
\text { Difference }\end{array}$} & $\begin{array}{l}95 \% \text { Confidence Interval of the } \\
\text { Difference }\end{array}$ \\
\hline & & & & & Lower \\
\hline VAR2 & 0.423 & 905 & 0.672 & 8.913 E-03 & 5.023 E-02 \\
\hline
\end{tabular}

The above table shows that $\mathrm{Sig}=0.672$ more than $5 \%$ which means that there is a statistically significant effect between students violence and students themselves and psychological, economical and social factors.

\subsection{Third Hypothesis}

There is a statistically significant effect between student's violence and the reasons related to teaching staff

Table 7 shows that mean for the third domain (reasons related to teaching staff) is high, so there is a statistically significant effect between students violence and the reasons related to teaching staff.

Table 11. Significance level of the third domain (ONE SAMPLE TEST)

\begin{tabular}{|c|c|c|c|c|c|c|}
\hline & \multicolumn{6}{|c|}{ Test Value $=3.8$} \\
\hline & \multirow[t]{2}{*}{$\mathrm{T}$} & \multirow[t]{2}{*}{ Df } & \multirow[t]{2}{*}{$\begin{array}{l}\text { Sig. } \\
\text { (2- tailed) }\end{array}$} & \multirow[t]{2}{*}{$\begin{array}{l}\text { Mean } \\
\text { Difference }\end{array}$} & \multicolumn{2}{|c|}{$\begin{array}{l}95 \% \text { Confidence Interval of th } \\
\text { Difference }\end{array}$} \\
\hline & & & & & Lower & Upper \\
\hline VAR3 & -1.397 & 905 & 0.163 & $-6.251 \mathrm{E}-02$ & -0.1504 & $2.534 \mathrm{E}-02$ \\
\hline
\end{tabular}

The above table shows that $\mathrm{Sig}=0.163$ more than $5 \%$ which means that there is a statistically significant effect between students violence and the reasons related to teaching staff.

\subsection{Fourth Hypothesis}

There is a statistically significant effect between student's violence and reasons related to other factors

Table 8 shows that mean for the fourth domain (and reasons related to other factors) is high, so there is a statistically significant effect between student's violence and reasons related to other factors. 
Table 12. Significance level of the fourth domain (ONE SAMPLE TEST)

\begin{tabular}{|c|c|c|c|c|c|c|}
\hline & \multicolumn{6}{|c|}{ Test Value $=3.88$} \\
\hline & $\mathrm{T}$ & Df & $\begin{array}{l}\text { Sig. } \\
\text { (2- tailed) }\end{array}$ & $\begin{array}{l}\text { Mean } \\
\text { Difference }\end{array}$ & $\begin{array}{l}95 \% \text { Confidence } \\
\text { Difference }\end{array}$ & Interval of the \\
\hline & & & & & Lower & Upper \\
\hline VAR4 & 0.217 & 905 & 0.828 & 3.948 E-02 & -3.17 E-02 & 3.964 E-02 \\
\hline
\end{tabular}

The above table shows that Sig $=0.828$ more than $5 \%$ which means that there is a statistically significant effect between students violence and reasons related to other factors.

From the previous results, it is obvious that respondents placed nepotism at the top of all items regarding university policies and management. This asserts the negative effect of nepotism phenomena as one of the main causes leading to violence in the campus because it involves unfair distributing of chances. This result highlights the importance of confronting this phenomenon and to put limitation to its dangerous consequences. However, loan system in the university accorded the lowest rank among the causes of violence as perceived by the respondents which indicate that it is not an important factor of violence.

With regard to the Second domain (reason related to students themselves and related to psychological, economical and social factors), Tribal fanaticism between students recorded the highest rank among other causes with means 4.69. This indicates that tribal fanaticism and its consequents play a significant role in causing and increasing violence which is necessary to overcome. This result agrees with previous studies such as Hawamdeh 2003 and Saleh 2005 studies. This may be due to the tribal structure which marks the Jordanian society, as well as different traditions and customs that help in rooting fanaticism.

On the other hand, lack of participation was the less important factor among all factors with means 2.80 . This means that student's participation in lectures is not a main cause of violence according to the responses.

In respect of reasons related to other factors, tribal effects on the society has a high significant with means 4.5 indicating that individuals are largely influenced with their tribal attitudes, and that tribal fanaticism is clearly reflected on the relationships between students and $\mathrm{n}$ the society.

The results also showed that local and international media is less significant factor in student's violence. This result could be attributed to role of multimedia in reducing the phenomenon of violence, and shows that media is tries to spread awareness.

\section{Conclusion}

The current study concluded that the major causes of violence as reported by the respondents included tribal fanaticism, nepotism, tribal effects on the society, not respecting students and improper treatment. Furthermore, Psychological stress and disorders, weakness of the religious restrain and bad investment of free time were important causes of violence.

\section{Recommendations}

In light of these findings, the following suggestions are recommended:

- Avoid nepotism, focus on objectivity in marks giving and avoid bias.

- Focus on principles of tolerance, and rejection of intolerance and fanaticism.

- Training staff members and administrators on how to deal with the university students.

- Enforce effective punishment systems and procedures for violence motivators and people who use nepotism, as well as all kinds of discrimination.

- Increase the role of media and internet and produce programs to overcome violence, especially those delivered to youth.

- Making campaigns and activities to spread awareness of the dangerous consequences of violence.

- Prepare workshops to enhance the culture of accepting the other and respecting other's culture, as well as the culture of dialogue and problem solving strategies instead of violence.

- The university must know how to deal with violence events, and should be ready to control fights through a previously prepared plan. 
- Good investment of free time through enhancing reading, using new teaching methods, participating in extra-curricular activities, and encouraging students to participate in theoretical and field research inside and outside campus.

\section{References}

Al-Atiat, K. (2010). Applying Non-Violence According to the Students of Al-Hussein Bin Talal University. European Journal of Scientific Research, 42(3), 464-477.

Alhawamdeh, K. (2003). Zarqa University: A Jordanian study. Amman center studies. Retrieved from http://www.amanjordan.org/aman_studies

Alhawamdeh, K. (2007). Student violence in Jordanian public and private universities according to student viewpoints. Zarqa University, Jordan.

Al-Louzi, S. H., \& Farhan, Y. I. (2009). Students' Violence at the University of Jordan. Jordan Journal of Social Sciences, 2(2).

Hawamdeh, Z. M. (2007). Evaluation of Physical Growth in Cerebral Palsied Children and Its Possible Relationship with Gross Motor Development. International Journal of Rehabilitation Research, 30(1), 47-54. http://dx.doi.org/10.1097/MRR.0b013e328013dad8

Kim, M. (2005). Defense mechanism and self-reported violence toward strangers. Bulletin of the Menninger Clinic, 96(4), 305-312. http://dx.doi.org/10.1521/bumc.2005.69.4.305

Okour, A. M., \& Hijazi, H. H. (2009). Domestic Violence and Family Dysfunction as Risk Factor for Violent Behavior among University Students in North Jordan. Journal of Family Violence, 24(6), 361-366. http://dx.doi.org/10.1007/s10896-009-9235-6

Shwiehat, S., \& Akroush, L. (2010). The Causes of Students' Violence in the Jordanian Universities. Jordan Journal of Social Sciences, 3(2).

Wiley, J. (2001). Student violence and the moral dimensions of education. Psychology in the Schools, 38(3), 249-258. http://dx.doi.org/10.1002/pits. 1015

\section{Copyrights}

Copyright for this article is retained by the author(s), with first publication rights granted to the journal.

This is an open-access article distributed under the terms and conditions of the Creative Commons Attribution license (http://creativecommons.org/licenses/by/3.0/). 